\title{
Waging a professional turf war: an examination of professionalization as a strategic communication practice used by registered dietitians
}

\author{
Sarah N. Heiss, ${ }^{1}$ Kristin K. Smith, ${ }^{2}$ Heather J. Carmack ${ }^{3}$ \\ ${ }^{1}$ Department of Community Development and Applied Economics, University of Vermont; ${ }^{2}$ Department of Earth Sciences, Montana \\ State University; ${ }^{3}$ Department of Communication Studies, University of Alabama, USA
}

\begin{abstract}
In 2012, the American Dietetic Association changed its name to the Academy of Nutrition and Dietetics. The following year, the association allowed their members to select between two titles: registered dietitian (RD) or registered dietitian nutritionist. Based on interviews with dietitians, we argue that these semantic changes added fuel to a pre-existing discursive struggle for professional legitimacy. As of June 2017, there were over 100,000 registered dietetic practitioners, globally. Approximately 74\% of RDs are members of the Academy, a notably high percent of representation, suggesting the influence of this professional organization on the occupation. Academy members work in a variety of occupational settings and fields, including hospitals, nonprofit organizations, and the food industry, and as such make significant contributions to patient health and public health outcomes. The Academy and its members have established a discursive turf war to strategically establish and defend boundaries within the field of nutrition and dietetics. Their discursive turf war has implications on the day-to-day work life of registered dietitians and other nutritional professionals as well as perceptions of professionalism made by audiences outside the field.
\end{abstract}

\section{Introduction}

In January 2012, the Academy of Nutrition and Dietetics - the leading professional association for registered dietitians (RDs) - did something it had never done before in its 95-year history: it changed its name. Once the American Dietetic Association, its new name, the Academy of Nutrition and Dietetics, was chosen to better communicate its mission while promoting the strong science background and academic expertise of [its] members. ${ }^{1}$ A year later, the Academy announced that dietitians could now choose their preferred title, Registered Dietitian or Reg-

Correspondence: Sarah N. Heiss, Department of Community Development and Applied Economics, University of Vermont, USA. E-mail: sarah.heiss@uvm.edu

Key words: Professionalization; Professional boundaries; Health communication; Organizational communication.

Funding: grants from Vermont Agricultural Experimentation Station Competitive Hatch, during the conduct of the study.

Received for publication: 23 February 2018.

Revision received: 20 August 2018.

Accepted for publication: 26 August 2018.

This work is licensed under a Creative Commons Attribution NonCommercial 4.0 License (CC BY-NC 4.0).

CCopyright S.N. Heiss et al., 2018

Licensee PAGEPress, Italy

Qualitative Research in Medicine \& Healthcare 2018; 2:121-131

doi:10.4081/qrmh.2018.7376 istered Dietitian Nutritionist (RDNs). Both the RD and the RDN titles require the same education requirements, certification processes, scope of work, and regulation. The Academy reinforced the importance of choosing a title in their 2014 Media Guide, saying, All registered dietitians are nutritionists, but not all nutritionists are registered dietitians. This is a distinction that can matter a great deal to people's health. ${ }^{1} \mathrm{RDs}$ and RDNs are empowered to select the title that best fits their work and perceived audience's preferences.

These title changes are more than simple changes in semantics. They hint at deeper tensions and ongoing conflicts regarding who gets to be the gatekeeper of nutritional knowledge - registered dietitians or nutritionists. The Academy's name change and adoption of the RDN title suggest that, despite being a regulated profession, the Academy is actively and purposefully engaging in professionalization, which includes the discursive processes that workers, as individuals and collectives, use to attain and maintain professional legitimacy for their occupation or profession. ${ }^{2}$ Positioning RDs as the nutritional experts in the United States gives RDs the exclusive right to provide nutritional advice and services. It limits the rights of nutritionists and other health care professionals.

This study examines the professionalization practices used by RDs and their professional association. Specifically, we examine how RDs strategically frame and organize their identities to establish themselves as the nutritional professionals. We also seek to understand RDs' perceptions of how their professionalization discourses affect their profession and other professions. We argue that the Academy and its members established a discursive turf war between RDs and nutritionists as a way to 
increase their profession's legitimacy and economic security. Our analysis of the RD's turf war examines the boundary dynamics within nutritional healthcare provision and has valuable implications for RDs and nutritionists alike.

\section{Nutritional healthcare providers}

Dietetics grew out of the field of home economics, a history that has enabled and constrained the profession's identity and legitimacy in healthcare contexts. ${ }^{3,4}$ While dietitians first organized themselves as part of the American Home Economics Association (AHEA), they broke off from this group and formed the American Dietetic Association (ADA) in $1917 .{ }^{5}$ The ADA was exclusively for individuals who were officially trained and educated in home economics and/or dietetics. ${ }^{5}$ The ADA attempted to leverage the exclusivity of its membership to create legitimacy in health care contexts, which dismissed or diminished the value of nutritional health care: "the true dietitian when properly trained and experienced is a specialist and deserves that recognition in the hospital." ${ }^{\prime 3}$ To bolster the legitimacy of RDs further, the Academy pointedly used positivist and scientific language to frame its purpose and goals. In 1955 the president of the Academy explained its mission was "to improve the nutrition of human beings, to advance the science of dietetics and nutrition, and to advance education in these allied areas." ${ }^{3}$ The Academy's continual emphasis on science, research, and expertise aligned it with academia and elevated the profession. The profession also set minimum requirements to be a member to help differentiate dietitians' medical and scientific expertise.

As of June 2017, there were over 100,000 registered dietetic practitioners, globally. ${ }^{1}$ Approximately $74 \%$ of RDs are members of the Academy, ${ }^{6}$ a notably high percent for professional associations. Academy members work in a variety of occupational settings and fields, including hospitals, nonprofit organizations, and the food industry, and as such make significant contributions to patient health and public health outcomes. ${ }^{1}$

While the profession remains quite diverse, its practitioners are unified through their RD credential and, for many, their Academy of Nutrition and Dietetics membership. To become registered, dietitians must complete a bachelor's degree from a certified program, finish a six to twelve month internship, and pass a national certification exam. Once registered, dietitians are required to pay an annual registration maintenance fee, to complete 75 continuing education credits every five years, and to submit a professional development portfolio to remain certified. ${ }^{1,3}$ In addition, many states require dietitians to obtain a stateissued license - with its own structure and rules - in order to practice in that location. The national and statewide certification processes are important legitimacy symbols that set dietitians apart from other food and nutrition professionals.
Recently, the Academy made several title changes to address a professional tension within nutritional professions. First, the association changed its name, and second, it now offers two credential designation options: RD or $\mathrm{RDN}$. The Academy explained that the inclusion of the word nutritionist in the $[R D N]$ credential communicates a broader concept of wellness (including prevention of health conditions beyond medical nutrition therapy) as well as treatment of conditions ${ }^{1}$ designed to increase the general public's and non-experts' awareness of the field of dietetics. Incorporating the word nutrition into the association's legal name increased its online media impressions from 20 billion prior to the name change to 30 billion. ${ }^{1}$ The Academy argued the name change helped to optimize its presence among the public and non-experts who were searching for nutrition information.

While incorporating the term nutrition(ist) was designed to increase the scope of work and awareness of the dietetics profession by drawing on the term's familiarity, the new labels also served to help distinguish the knowledge and services of dietitians from those provided by nutritionists. The label nutritionist is used to identify someone who provides nutritional advice; however, formal requirements governing the provision of nutritional advice vary from state to state, with a wide range of rules, educational requirements, and certification types. ${ }^{1}$ Furthermore, there are also special requirements for those performing nutritional work related to specific agencies, such as health care providers and government reimbursement programs. In the United States, a nutritionist may be someone who obtained a certification or degree in nutrition and works in research, health, or educational contexts. However, in some states, it is also legal for a person who provides nutritional advice with little to no formal education in nutrition, such as a health food or supplement salesperson, to use the nutritionist label.

RDs are nutritionists because they are nutritional experts; however, not all nutritionist can claim the RD title. To claim the RD title in the United States, one must meet the specific academic and professional requirements of the Academy's credential process (the data collected for this manuscript was collected after the Academy changed its name but before it changed the credential options - RD or RDN - for individual members. As such, we decided to refer to individual registered dietitians as RDs - the only label option Academy members had at the time of data collection. We use the label RDN in the manuscript to highlight current and future symbolic conditions). The new label helps to address overlapping scopes of practice to enable efficient and effective client-centered services.

The recent name and credential changes demonstrate a new chapter in RDs' ongoing struggle with professionalization. A study of Canadian dietitians found that many RDs reported being felt disappointed that they never obtained the level of professionalism promised to them during their educational training. ${ }^{7}$ The Academy has 
acknowledged similar struggles. In the organization's $70^{\text {th }}$ anniversary book published in 1990, the editor noted that another long-standing problem was the profession's seeming lack of self-confidence. ${ }^{4}$ The current study seeks to examine contemporary attempts by RDs and their professional organization to strategically frame their identities as professionals as well as distinguish their profession's scope of practice from other related occupations.

\section{Communicating professionalization}

Professions claim expertise in specialized areas of knowledge and skills. In return, the public and other nonexpert professionals frequently look to them for expert advice or services. Attaining professional legitimacy is important because it allows the profession to develop, maintain, and affect organizational and work life, as well as the development and diffusion of expert knowledge.

While professions are important, professional legitimacy of any job is not given or pre-determined. An occupation does not have a predefined set of properties or features needed to obtain recognition as a profession. ${ }^{2}$ Rather, professional status reflects a precarious set of ongoing, co-constructed definitions and public performances of competence, scope of work, and occupational identity.

Professionalization discourses are fundamentally rhetorical process [es]. ${ }^{2}$ Professionalization discourses represent workers' attempts to make sense of who they are and what they do in relation to their jobs. ${ }^{8}$ Workers, as individuals and collectives, have active roles in staking a claim to their sphere of competence, defining their scope of work, and setting expectations regarding intra- and inter-professional interactions. ${ }^{2}$ However, the agency of a given profession to set its boundaries is bound by the larger social structures in which it exists. Professionalization discourses are dynamic social negotiations that shape and are shaped by culture, norms, politics, institutions, and history within and outside of a given profession. Professionals, as individuals and collectives, are simultaneously a product of and contributor to their historical moment. This approach helps contextualize professions as existing in a larger complex social system of interconnected occupations that strategically exclude and include groups of workers.

\section{Professionalization boundaries and strategies}

Torstendahl shifted scholarly theorizing about professionalization discourses by adopting a strategic approach. ${ }^{9}$ This approach accounts for the dynamic nature of professions and situates workers, as individuals and collectives, as having active roles and purposeful goals in professionalization. Adopting a strategic approach, Esser and Tenscher described professionalization discourses as an on-going strategic attempts to present an occupation as the only competent and responsible group to tackle a specific problem. ${ }^{10}$
Professionalization discourses can be understood as a set of strategic boundary setting practices. ${ }^{11,12}$ Professional associations and individual workers distinguish their expertise, skills, and services from those of other occupations. By doing so, professionalization establishes arbitrary professional boundaries that include certain individuals and exclude others.

While professions may be able to reach mutually agreed upon boundaries, boundary setting has also been described using combative terms. Professional boundary work has been described using a battlefield metaphor, ${ }^{11}$ wherein different kinds of experts and even non-experts fight for the right to determine who has professional legitimacy and, therefore, occupational jurisdiction or turf. Discursive battles for turf and professional legitimacy determine which occupation's advice and services are accepted as permissible, autonomous, or valuable to social policy, organizational practices, and members of the general public. ${ }^{13}$ By gaining monopoly over a certain area of expertise, occupations achieve market control, respectability and social status in the community. ${ }^{14}$

Nanacarrow and Borthwick argued that the dynamic role of boundaries have the potential to challenge the monopoly of all the healthcare professions. ${ }^{15}$ Indeed, professional boundary setting discourses have been identified as occurring in many healthcare contexts, including but not limited to disputes between traditional, complementary, and alternative medicine ${ }^{16}$ and nursing and midwifery. ${ }^{17}$ In addition to inter-professional boundaries, professionalization discourses can also establish intra-professional boundaries. ${ }^{15}$ By creating co-cultures, specified scopes of practice, and new formal associations, professions can strategically segment parts of a profession from the whole. In addition to differentiating scope of practice, intra-professional boundary setting often establish hierarchy among segments.

Professionalization within the healthcare context includes a variety of discursive and institutionalized practices. First, specialized expertise, often scientific in nature, is often cited as differentiating between in-group and outgroup healthcare providers. ${ }^{17}$ Second, occupations tend to emphasize holism and patient centeredness to establish that they are able to treat the whole patient within very specific circumstances. ${ }^{18}$ Third, occupations stress their ability to simultaneously provide emotional reassurance to patients and medical care. ${ }^{18}$ Fourth, occupations promote their ability to prevent problems, while others treat the symptoms. Fifth, occupations commonly adopt professional licensure and credential programs to set firm boundaries regarding their professional turf and assert their professional accountability. ${ }^{2,18}$

\section{Professional outcomes of boundary setting}

Establishing and maintaining a discursive turf war over professional boundaries has important implications for those included, those excluded, and patients. First, 
healthcare systems around the world are adopting interprofessional collaborative care models. ${ }^{19}$ Continually evolving external and internal professional boundaries supports a clearer division of labor and reduces the potential for conflict when workspaces of different occupational groups overlap. ${ }^{10}$ Second, professional boundaries maintained with regulations, licenses, or certificates provide a level of professional accountability. ${ }^{18}$ By expecting certain levels of professional competency, these practices protect the public from incompetent practitioners. ${ }^{20}$ Professional endorsements also help healthcare consumers and potential employers easily identify credible professionals. In addition to helping providers and consumers find qualified advice and services, professional boundaries serve to protect healthcare providers from litigation. For example, regulations, licenses, and certificates in the field of nursing standardized nursing care, protecting the general public by reducing medical mistakes and protecting nurses from litigation due to medical mistakes. On the other hand, the National Center for Complementary and Integrative Health argued, regulations, licenses, or certificates do not guarantee safe, effective treatment from any provider - conventional or complementary. ${ }^{21}$

Third, by establishing clear professional boundaries occupations are able to self-regulate work. ${ }^{12}$ At the macroorganizational level, self-regulation represents the autonomy of an occupation to dictate guidelines for training, development, and practice. Autonomy is also represented in micro-organizational practices, where many professionals now work on inter-professional allied health teams. Professionalization claims jurisdiction over specialty services and provides autonomy from other medical professionals, which increases the likelihood of being able to bill for care. ${ }^{13}$

Sela-Sheffy and Shlesinger argued that examining professional boundary work is particularly useful for studying a range of different processes in the construction of professions. ${ }^{14}$ While boundary work has been identified in some research as a key outcome of professionalization processes, researchers have yet to talk to actual workers about their motivations and strategies related to professionalization and boundary management. In this study, we understand RDs as a professional social group, united by the Academy, which has and continues to engage in professionalization processes to attain and maintain their professional legitimacy as the nutritional care providers among food and nutritional experts, as well as health care professionals within a larger healthcare contexts. The current project adopts a communicative-based approach to understanding how workers' in the field of dietetics understand and strategically frame their individuals and collective identities as professionals to achieve professionalization. We also discuss the possible implications of these professionalization discourses on their occupation and related-occupations. Specially, we ask,

RQ1: How do RDs discursively frame and organize their identities to establish their profession legitimacy?

RQ2: How do RDs' discursive choices serve to affect their profession and related-occupations while also seeking the right to provide nutritional care?

\section{Materials and Methods}

This study was supported with funds from a competitive Agricultural Experimentation Station Hatch grant. The grant funded project originally focused on partnerships between the Academy and the food industry. Data collection began after the researchers received university Institutional Review Board approval.

\section{Participants and data collection}

Seventeen participants were recruited through an initial group of key Academy member informants and snowballing techniques. To participate, interviewees had to be RDs or RDNs who were past and/or current members of the Academy. The first and second authors recruited participants through email from three stratified sample populations: authors of recently published articles in nutrition and food science journals, authors of popular nutrition blogs, and faculty from university nutrition and dietetic programs. To increase the diversity of our sample, we used snowball sampling, in which interviewees recommend other potential interviewees.

Interviewees represented a diverse subset of Academy members. The age of interviewees ranged from 20 years old to 66 years old $(M=39)$. The number of years spent as an Academy member varied from less than one year to over 38 years $(M=13)$. Fourteen of the interviewees identified as female $(82.3 \%)$ and three interviewees identified as male $(17.6 \%)$. Approximately $88 \%$ of interviewees identified as Caucasian $(n=15)$, with one interviewee identifying as Hispanic and one interviewee identifying as Asian. Professionally, the interviewees ranged from having less than one year of experience to more than 30 years as a RD. Interviewees worked in a variety of settings, including hospitals, universities, public health settings, and the corporate food industry. Three interviewees identified as current students, and one interviewee identified as a doctoral student. The participants hailed from 13 states and the District of Columbia.

\section{Interviews}

The first and second authors conducted face-to-face, semi-structured interviews during the 2012 Food and Nutrition Conference and Expo (FNCE). Interviews took place in quiet, private locations near the FNCE venue. Interviews took place over four days. The first and second authors completed follow-up phone interviews after the event with RDs who could not attend an interview during FNCE or to obtain follow-up information. Interviews lasted approximately 45-60 minutes. 
The first and second authors developed an interview protocol and research plan prior to attending FNCE. Based on the nature of the grant, questions focused on RD's experiences and attitudes related to organizational partnerships between the Academy and the food industry. Questions included broad questions related to the RD occupation and the Academy, including the average RD workday, the perceived importance of the Academy to RDs, and Academy-industry partnerships and their impacts on public perceptions of RDs.

Semi-structured interviews follow a preconceived interview script, but also give the interviewer freedom to digress to explore emergent themes. ${ }^{22}$ At the end of each interview and the end of each day, the first and second authors reflected together on the content of the interviews. The original interview protocol focused on RD's perceptions of Academy partnerships with industry. After several interviews, we noticed a reoccurring defensiveness from participants. Interviewees constantly redirected the discussions by highlighting their individual and collective expertise and by telling stories that emphasized their individual and group professionalism and the differences between dietitians and nutritionists. After identifying these patterns within the first five interviews, we added questions about professions and professionalization to the original interview protocol. The new questions included, what does it mean to be a professional in the field of nutrition and dietetics? What is a dietitian? What is a nutritionist? How does the Academy help you attain or maintain professional status?

\section{Data analysis}

We used constant comparative methods to inductively identify themes in the data. Constant comparative analysis is a cyclical and continuous method of processing, reducing, and explaining. ${ }^{22}$ Researchers continually identify codes and themes within and across interviews as well as in comparison to the extant literature. Analysis starts during the data collection process and calls for the continual refinement of themes as data is collected and then formally analyzed, through constant comparisons and recoding of the data set. ${ }^{23-25}$

During data collection, issues related to profession were consistently mentioned across all interviews. As themes emerged during data collection, the first and second author compared themes with other interview cases and previous research to understand how they confirmed, expanded and/or diverged from previous scholarship. The themes were so forceful and reoccurring, that we stopped interviewing when we reached saturation on this theme of professions, rather than the original aims of the project.

Interviews were transcribed verbatim, resulting in 292 single-spaced pages. In our initial analysis, the first and second authors read and coded the transcripts multiple times independently until forceful and recurring themes began to emerge from the data. The first and second au- thors discussed their codes and collapsed related codes into each other while dividing other codes to offer more detail as patterns began to emerge. The authors then reread and re-coded the data independently before meeting to discuss the data again. This iterative process continued until no new codes or themes emerged. We used forceful and representative quotes from the interviewes to represent the interviews' unique voices and to support our claims as researchers. The third author joined the project after the analysis process was complete to help with writing and revising the written manuscript for publication.

\section{Results}

Based on our analysis of the interview transcripts, RDs - as individuals and a collective united by the Academy - are actively engaged in on-going professionalization struggles. Specifically, RDs are employing a discursive turf war as a professionalization tactic to claim jurisdiction over the provision of nutritional counseling and care. This turf war establishes boundaries of expertise between dieticians and nutritionists to establish legitimacy within an already tenuous healthcare landscape for nutritional experts. We argue that this turf war is fueled by unmet professional expectations. After establishing the discursive exigency for a turf war, we highlight the discursive practices that comprise this professional turf war. We discuss the possible implications of these professionalization processes on dietetics and related-occupations.

\section{Setting the grounds for a turf war}

During discussions of the Academy, RDs continually justified their profession and their training. They emphasized how hard they worked, how long they spent in school, and how they were diligently trained in objective, scientific research methods. Despite having bachelor's degrees or more advanced professional degrees, members often voiced complaints of being underpaid. One RD argued, There should be more recognition in terms of pay and things like that for people who have spent some time... and effort into becoming an expert that they might not be recognized for right now in terms of pay or position. Their comments underscored frustrations with the misunderstandings related to how people view their field. Moreover, the dietitians used these arguments as ways to prove their value - and their status as professionals. One member described the process of becoming an RD as really difficult. Much more difficult than people realize.

Salary is associated with legitimacy and status, and the lack of it was a catalyst for RDs' frustrations. One RD explained, dietitians are not super well paid, especially for half our workforce having a master's degree or higher education level. She went on to compare dietetics to other health professionals to emphasize this inequity. I think that we make less than half of what the pharmacists at our 
hospital make, and other - and like the P.T.'s and things like that - and the O.T. 's... And I have a master's degree and I make less than half of them. In order to counter their perceived unequitable salaries, members reported having multiple jobs. One RD explained that she strings things together by working a clinical job at a long-term care nursing facility, an advising job at a college campus, and a nutritional messaging job with a food service company. The participants who identified money as a reason for frustrations also talked about a perceived wage ceiling within the occupation and greater professional inequalities within the health field. Many members of the Academy felt that they were paid less than other health professionals, though they had similar or higher levels of educational training and/or experience.

Members frequently voiced frustration that other healthcare providers and the general public did not understand the dietetics occupation or differentiate it from other nutritional professions. Many doubted that the Academy was known outside of specific public health circles and wondered if the public understood the occupation's value. Members repeatedly told stories about how RDs were often confused with nutritionists, which they perceived as negative. Academy members lamented this confusion, suggesting that it dismissed RDs' specialized training, skill set, and expertise. One dietitian began her interview by assuming that this was a common theme in other interviews: And I'm sure you've probably heard that before where people-you talk to people, you want to be a dietitian, and they're like, what is that. So we're really trying to get that information out there. Another member commented that, when he gave public lectures, the audiences rarely understood the difference between nutritionists and dietitians: They all have that kind of confusion. So it's nothing new... But at least luckily I have the opportunity to tell some people. As RDs made sense of who they were in relation to their jobs, they struggled with the perception that their profession lacked status and public recognition. Further, they continuously voiced frustration about the confusion between dietitians and nutritionists, emphasizing the need to frame the RD profession as distinct from and more legitimate than other nutrition professions.

Academy members' stories and frustrations suggest that their expectations for professionalization are not being met. Interviewees reported specifically not feeling respected as professionals by the public and by other healthcare professionals. They also were concerned that they were being underpaid for their professional-level services. To legitimize and elevate their profession, members strategically created a discursive turf war to set professional boundaries between nutritionists and dietitians.

\section{Constructing a turf war}

Members' stories about unequal pay and public confusion about their occupation suggest that, despite being members of a regulated profession, RDs are still working to achieve professionalization. Their comments reflected continuity with earlier identity work that suggested, dietitians have a melancholia... associated with lack of recognition, loss arising from unfulfilled promises of professionalism and spiritual injury. ${ }^{7}$ Their unmet professional expectations included disappointment that they were not seen as having nutritional expertise that is different from nutritionists. All of these frustrations created a space for a professional turf war between dietitians and nutritionists. Academy members create a discursive turf war by i) (re)claiming nutritional expertise and ii) crafting monetary legitimacy.

\section{(Re)claiming expertise}

Academy members feel professionally marginalized. Weick et al. argued that individuals use organizational sensemaking to organize unmet expectations. ${ }^{26}$ Sensemaking is a communication process that seeks to answer what's going on here and what do I do next. ${ }^{26}$ When faced with perceived marginalization, members of the Academy used organizational sensemaking to claim control over formal nutritional knowledge and (re)define themselves as professionals. This process involves categorizing, labeling, and creating hierarchies to bring order to their occupational identity. ${ }^{26}$ To legitimize and elevate their profession, members used turf war rhetoric to create a hierarchy of nutritional professionals. As one member put it, Really there are turf wars happening in the states on who gets to practice as a Dietitian or practice the practice of nutrition. And Dietitians fight long and hard to have the control of the nutrition field. Drawing on this RD's comment, we describe the material, discursive, and organizational practices that Academy members used to bound their profession through a rhetorical turf war.

Academy members symbolized and communicated their expertise by discussing their education and RD certification to differentiate their profession. One member compared his education to basically [getting] a pre-med degree, while another emphasized that over $50 \%$ of dietitians who are practicing and [are Academy] members also have a master's degree, so that's at least five to six years of education on top of their internship. Members described their $\mathrm{RD}$ certification as culminating proof of their extensive training and as validation of their expertise. As described by one member, it is a credential that means that you have a certain set of skills that you have... mastered and demonstrated your mastery of. Another member used her certification to illustrate her journey to becoming a professional. She emphasized the specific course load of work that you have to do, undergraduate, bachelor's degree work in sciences -in nutritional sciences and food safety. She then noted the exam that RDs must pass to become registered and discussed her profession as a certified practice. This member went into great detail about how she became a professional, noting the specific, bureaucratic symbols and milestones along the way, such as her course load and the 
exam. Other Academy members also made claims to professionalism by discussing the milestones - like their education and certification - that best communicated their journey to becoming professional. In this view, the profession is framed as an achievement to be gained after long years of hard work.

Members' descriptions of their profession as an achievement starkly contrasted with how members described and defined a nutritionist. While RDs self-defined themselves as specialized, scientifically trained professionals, nutritionists were continually described as having an unknown level of expertise and status. One member described a nutritionist as anyone that self-proclaims as an expert - and they don't even have to say expert, but just someone who gives nutritional advice. Another member further explained, the term nutritionist is not defined. It's undefined. So you could read a book about diets or a book about nutritional science and call yourself a nutritionist. Anyone can call themselves a nutritionist because it's not overseen by an entity. Others went even further and described nutritionists as lacking any practical experience in public health and nutrition. While the $\mathrm{RD}$ process is highly structured, bureaucratic, and framed as legitimate, members described nutritionists as having varying - often-unknown - degrees of expertise.

By contrasting nutritionists' occupational ambiguity with the highly specific regulations of RDs, Academy members created a nutritional Other. Members drew on the nutritional Other to communicate what it is that they are not: nutritionists are undefined; RDs are certified; nutritionists are amateurs or have ambiguous educational backgrounds; $\mathrm{RD}$ are carefully regulated and therefore legitimate. Members used nutritionists - as the Other - to elevate their own profession. One member noted, As far as job descriptions go...RD is kind of a distinction and level of education whereas... anyone that wants to call themselves a nutritionist, they don't really have to have anything to verify that. This strategy fits into Ashcraft, Muhr, Rennstam, and Sullivan's review of the literature on how professions are crafted. ${ }^{27}$ They argued that the construction of professions entails not only aligning occupations with particular people, but also contrasting them with lowly Others. ${ }^{27}$ Those that are excluded from the profession are therefore a necessary part of occupational identity. The implication is that, while members often complained about nutritionists, they are actually an important component of how members made sense of their occupational identity and claimed expertise.

To make sense of their unmet occupational expectations, members framed themselves as more educated, trained, and/or legitimate than nutritionists, drawing a hierarchy of expertise within the nutritional field to strategically create professionalization. As one member succinctly explained, $A$ dietitian is a higher level than a nutritionist. Some members added to the hierarchy by comparing RDs' work to health professions that are al- ready seen as legitimate, such as doctors or physicians: So, what I'd like to see is in the future the dietitian is recognized as important as the doctor. When we talk about nutrition as a preventive medicine, it's important. The hierarchy creates an us (RDs) and a them (nutritionists) dichotomy that RDs use to claim expertise for their profession. This hierarchy is thus one way that members labeled, categorized, and ordered their work to make sense of their occupational identity. Despite this constructed hierarchy, members often noted that while this hierarchy might be true in their opinion, the public still did not understand this difference.

\section{Crafting monetary legitimacy}

Given RDs' unmet professional expectations, particularly around salaries and perceptions of legitimacy, members looked to the Academy to increase economic benefits for their profession. Members discussed the Academy as an important resource for helping to differentiate between nutritionists and RDs and to elevate the profession of dietetics. For example, one member noted how the Academy defined the dietetic profession by describing a page on the Academy's website:

There's actually a link that simply breaks down the difference between a Dietitian and a nutritionist...the Academy plays a great role in that - in really trying to educate the public about the difference in the qualifications and how to safely choose a practitioner for their nutrition health care.

For these RDs, the Academy plays an active role in creating economic benefits for dietitians by promoting the turf war rhetoric to limit nutritionists' influence and scope of work.

Academy members discussed their desire to claim nutritional expertise for themselves so that their services and only RD services - would be reimbursable by insurance agencies. Many members advocated for state licensures that would differentiate the profession and, hopefully, allow exclusive insurance reimbursement opportunities. One member explained, Every state has an opportunity to have licensed Dietitians, just like every state license. She went on to describe the concept of state licensure and insurance reimbursements, especially given new healthcare laws, by comparing RDs to other medical professionals:

If you're a doctor, for example, or a physical therapist, you have a state exam and a state licensure which allows you to bill and collect payments. And in the state of Washington, we are not licensed Dietitians and the regulations are written for licensed health care professionals which could, depending on which way the political winds blow - could mean that Dietitians who are not licensed cannot be reimbursed.

Similarly, another member explained her participation in an advocacy group by saying that she wanted her profession to be at the front in terms of knowledge of food and nutrition to make sure that we're getting reimbursed 
for those services; where they already are being reimbursed for and then where we would like to see them be reimbursed for. RDs were very aware that their dismissal of nutritionists had economic implications.

These members' interest in insurance reimbursements highlights how the turf war rhetoric was being used as a professionalization strategy. As members differentiated themselves from other nutritionists, they sought to create greater exclusivity in their field. This reinforces Freidson's view that credentialing was designed to build an occupational cartel that has the exclusive right to offer specific services, a right sustained by the state..$^{13}$ The question over which nutritional professions are licensed and reimbursable - nutritionists, RDs, or both - is contested. By using the turf war to claim RDs as the nutritional experts, members hoped to become the only reimbursable nutritional experts.

RDs also viewed the Academy's professionalization strategies as extending beyond individual monetary benefits and having broader impacts for public health. When discussing the Academy's mission, one member noted, It is about positioning members as nutrition experts and it is about the health of the consuming public. While this member sees the value in establishing RDs as the nutritional expert, they also situate the changes as having the potential to positively influence public health outcomes. Other members mirrored their concern for public health, but were concerned about their ability to affect positive changes because they did not feel the public fully understood their claims to expertise. Commenting on why the Academy changed its name, one member said, if you say dietetics, people don't know what you're talking about. So, if you put that word "nutrition" in there, it helps them understand better. This member perceived lack of public support as the impetus for the name change and hoped that by changing the name the Academy would garner public support for the profession and subsequently improved health outcomes.

\section{Discussion}

RDs and their professional association, the Academy, are actively engaged in strategic communication to attain and maintain professional status. RDs have long had to establish and defend their professional legitimacy within the broader healthcare context. However, their contemporary struggle is marked by efforts to distinguish themselves as the nutritional experts while simultaneously excluding other occupations that provide nutritional advice and services, specifically nutritionists. Indeed, questions surrounding the differences between nutritionists and dietitians are pervasive and hinder professionalization. As Freidson argued, it is hard to justify a certification when another profession can seemingly do the same job using a different occupational title. ${ }^{13}$

The Academy has a page on its website that specifi- cally addresses the reasons behind its name change, noting that the new name better communicates who we are and what we do. We are the nutrition experts. ${ }^{23}$ The success of the name change, according to the Academy, also provided the catalyst to offer the new title, Registered Dietitian Nutritionist. The name was approved by elected members of the Academy's House of Delegates, as well as the organizational units that manage the RD credential. ${ }^{24}$ Thus, the changes to incorporate the word nutrition(ist) into the Academy and the RDN title suggest an institutional acknowledgement of the struggle between RDs and nutritionists as well as the Academy's response - to delineate professional identities by claiming nutritional expertise as its own.

We argue the individual RDs/RDNs as well as the Academy itself stand to gain from the incorporation of the word nutrition(ist), though this gain comes at the expense of other nutrition professionals. The title change serves to benefit individual professionals because it distinguishes between RDs/RDNs and nutritionists. Differentiating $\mathrm{RD} / \mathrm{RDN}$ knowledge and services will help members of the public identify qualified nutritional experts. This boundary setting activity also serves to establish/maintain the legitimacy of the $\mathrm{RD} / \mathrm{RDN}$ profession in the grander context of health care, by ensuring training and scientific grounding of RDs/RDN. In addition to the organizational discursive practices, we found that individual RDs/RDNs were interested in and actively engaged professional boundaries setting and spanning. Interviewees simultaneously claimed nutritional expertise as their territory and sought to differentiate and defend their profession from nutritionists.

In addition to supporting the professional legitimacy of $\mathrm{RD} / \mathrm{RDNs}$, these discursive choices also establish/reinforce the legitimacy of the professional organization itself. Organizational legitimacy enhances organization survival. By securing the recognition of the public and other relevant organizations, the Academy stands to increase competitiveness for resources (such as grants, sponsorships, and member dues). Additionally, organizational legitimacy makes the Academy a necessary and desirable social organization for those wanting to practice dietetics. The Academy is able to leverage their legitimacy to recruiting new $\mathrm{RD} / \mathrm{RDN}$ members. Its structured certification and continuing education process also ensures that $\mathrm{RD} / \mathrm{RDNs}$ continue to pay for their membership, conferences, conference materials, and educational credits.

\section{Theoretical implications}

Our findings contribute to and complicate past scholarship on professionalization. We found that a professional turf war discourse reflected a set of purposeful communication activities aimed at claiming $\mathrm{RDs}$ right to be the nutritional experts. Their turf war discourse strategically excluded the advice and services provided by nutritionists, framing RDs as the only competent and 
responsible group to address nutritional issues, according to Academy members. These findings align with theorizing of professionalization as a strategic process, ${ }^{9,10}$ and support a strategic communication-based approach to studying professionalization.

The use of purposeful turf war discourse as a rhetorical strategy is a novel contribution to theorizing professionalization. In addition to claiming jurisdiction over rights to membership and scope of practice, professional discourses of inclusion and exclusion can be used to create and foster conflict among experts as a way of legitimizing one group over the other. The potential ramifications of professional turf war discourses aimed at creating conflict and discord to establish legitimacy are concerning. Healthcare systems around the world are adopting inter-professional collaborative care models to better address complex health and wellness issues with the goal of improving patient and community outcomes. ${ }^{19}$ Professional territorialism on collaborative teams are a difficult barrier to effective collaboration and healthcare provision. To effectively engage in inter-professional collaborative care, team members will have to continually co-construct, maintain, and sometimes defend their professional legitimacy with all of these group members, clients, and communities. Dieticians and nutritionists have struggled to be seen as legitimate members of healthcare teams. ${ }^{6,28}$ By using conflict to achieve professionalization, professions exclude and diminish the legitimacy of a potentially close ally they have in their larger fight for legitimacy on collaborative health teams.

In addition to contributing to understandings of how a turf war can be used to professionalize, our findings also contribute to strategic communication-based understandings of professionalization by describing the attempted effects of the turf war discourse on professional boundaries. Past research has described professionalization as a set of discursive boundary setting practices most often between distinct fields, such as medical doctors and alternative health providers. ${ }^{16}$ Our findings highlight tensions present in the everyday use of a professional identity when it performs as a distinct identity from those of people who also offer similar occupational services, in this case the provision on nutritional care. Counter to previous claims that professional identity is fluid, ${ }^{2}$ the rhetorical turf war here shows how this fluidity is problematic when trying to stake a professional claim. Instead, the rhetorical turf war is about solidifying professional identity. Weick and colleagues argued that organizational sensemaking contributes to identity negotiations by using language, talk, and communication to organize chaos. ${ }^{26}$ By labeling nutritionists as undefined or amateurs, they use nutritionists as foils as a way to reinforce their occupational identities. Additionally, members used bureaucratic, objective symbols - such as their education and certification - to create a hierarchy in which RDs were shown to be more than nutritionists. By establishing the hierarchy, the turf war's message is clear: RDs are more qualified, more trained, more professional. Within the Academy, members participate in organizational sensemaking and identity negotiations by labeling, categorizing, and dismissing what they are not - nutritionists.

In addition to setting boundaries to distinguish their expertise, skills, and services from other related occupations (nutritionists), we found that RDs use a turf war discourse to also take away another occupation that has a scope of expertise and practice. This is a meaningful contribution to theorizing professionalization discourses. Turf war discourses can be both defensive and offensive. Professions can use the turf war discourse to maintain current boundaries and/or advance a profession's boundaries, at the exclusion of other occupations. Future research should compare and contrast boundary setting and spanning practices between fields that offer similar services as well as distinct services.

\section{Practical implications}

Our findings have practical implications for RDs and nutritionists alike. The turf war discourse currently being waged by dietitians and the Academy simultaneously highlights and diminishes RDs' identities as nutritionists. We argue that the fluidity of professional identities has benefits and drawbacks.

At the organizational level, the profession attempts to gain control over nutritional knowledge and services by incorporating the term nutrition(ist) into its formal titles. The Academy argued that these changes increased public awareness of the field and drove the general public and non-experts to the profession's formal knowledge. ${ }^{1}$ Indeed, a key to professionalization is that the public and non-experts are aware of the field and its advice or services. However, we found that the interviewees seemed bothered by the potential blurring of RD and nutritionist identities. When asked about the distinctions between RDs and nutritionists, interviewees recognized similarities and were able to clearly articulate differences. We also found that the interviewees tended to overcompensate with information that would bolster their performance of professional legitimacy. Specifically, interviewees emphasized the rigor of the accreditation process and their reliance on the scientific method. Interviewees reported using similar techniques to boost their performance of a competent professional when participating with inter-professional teams comprised of non-experts, such as other health care providers, directors of public health, or policy makers.

Our findings also highlight the interplay of material and social realities of professionalization. RDs were motivated to engage in turf war discourses as a way to establish professional legitimacy and exclusivity. Ultimately, their turf war stemmed from unmet professional expectations related to respect and compensation. A turf war discourse was thought to increase their monetary standing as a health profession. By limiting nutritionists' ability to 
provide nutritional services and advice, RDs hoped to become the only reimbursable nutritional experts, which, in turn, frames them as the only legitimate nutritional experts. Theoretically, this furthers Meisenbach's conceptualization of occupational identity. ${ }^{8}$ As Norander, Mazer, and Bates explained, The material realities of becoming a [professional] shape the ways in which [professionals] discursively construct the potentials and limits of their professions. ${ }^{29} \mathrm{By}$ using credentials and reimbursements to craft their professional identity, RDs rhetorically create the structures of their profession. Although this helps to create the clear boundaries of the profession, it also constrains future opportunities and growth.

What is most interesting about the potential gains and losses of the turf war discourse is that many RD interviewees voiced a long-history of unmet professional expectations, suggesting that, to date, professionalization strategies have not worked. The turf war discourses were reported to be motivated by unmet professionalization, which was ascribed in large part to the lack of clarity between the boundaries that separate nutritionist and RDs. However, it is very important for both RDs and nutritionists to consider if the lack of professional boundary clarity is the real issue. Professional identity is deeply rooted in conflicted, shifting, historical, cultural, gendered discourses. ${ }^{27}$ Past research has situated dietetics and nutritionists as gendered occupations that face a host of cultural challenges. ${ }^{3,28}$ Through this lens, waging an intraprofessional turf war with nutritionist is perhaps an ineffective professionalization strategy. We ask, are Academy members working to solve the right problem? By using the turf war discourses, RDs may be further marginalizing their profession and another already-marginalized occupation - the nutritionist. Perhaps, RDs and nutritionists should join efforts to address the larger cultural and historical constraints that bind both groups.

\section{Conclusions}

There are several limitations and opportunities for future research. First, our findings only reflect one voice in the turf war: the RD. Our focus on RDs reflects an indepth examination of one profession's purposeful attempts to claim and defend a professional turf. While an in-depth analysis is valuable, our findings are limited because they do not take into account the lived experiences or implications of the turf war discourse for other fields. Specifically, this analysis does not include the nutritionist's voice and experiences. However, more generally it also does not take into account how the turf war discourses are actually recognized or experienced by other providers in the health industry. Future research should investigate how turf war discourses are experienced by other healthcare professionals, including but not limited to, nutritionists. It would be interesting to examine what, if any, role these workers have in co-creating the turf war and potential impacts engaging or ignoring the turf war has on their work life.

In addition to examining the dynamic co-construction of the turf war, research should examine the broader cultural and historical discourses surrounding the professionalization of dietetics. We did not directly analyze historical and/or cultural discourses within and beyond the Academy's borders. Additional research is needed to understand how cultural and historic discourses are enabling and constraining the Academy of Nutrition and Dietetics and the occupation of dietetics. For example, research could examine discourses that support or challenge the hierarchical nature of medicine and health occupations in relation to one another. The social construction of power and authority of physicians within allied health care would be interesting to compare to that of dieticians. It would also be valuable to examine how cultural and historical discourses outside the health care arena shape the professionalization of medicine and health occupations. In the context of RDs, it would be interesting for future research to examine how media representations of food politics and public understandings of and trust in nutritional advice reflect, respond to, or shape professionalization strategies and outcomes.

\section{References}

1. Academy of Nutrition and Dietetics. Eat Right. 2018. Available from: http://www.eatright.org Accessed: 19 February 2018.

2. Cheney G, Ashcraft KL. Considering "the professional" in communication studies: Implications for theory and research within and beyond the boundaries of organizational communication. Commun Theory 2007;17:146-75.

3. Barber MI. History of the American Dietetic Association, 1917-1959. Philadelphia, PA: J.B. Lippincott Company; 1959.

4. Cassell JA. Carry the flame: the history of the American Dietetic Association. The American Dietetic Association; 1990.

5. Weigley ES. It might have been euthenics: The Lake Placid conferences and the home economics movement. Am Quart 1974:26:79-96.

6. Payne-Palacio J, Canter DD. The profession of dietetics : a team approach. Burlington, MA: Jones \& Bartlett Learning; 2014.

7. Gingras J. The passion and melancholia of performing dietitian. J Sociol 2010;46:437-53.

8. Meisenbach RJ. Working with tensions. Manage Commun Q 2008;22:258-87.

9. Torstendahl R. Essential properties, strategic aims and historical development: Three approaches to theories of professionalism. In Burrage MC, Torstendahl R, eds. Professions in theory and history: rethinking the study of the professions. London, UK: Sage; 1990. pp 45-61.

10. Esser F, Tenscher J. The professionalization dilemma: Exploring a strategic approach for political communication experts. Political Communication Division 2005. Proceedings of the at the International Communication Association Annual Conference. New York City, NY; 2005.

11. Larson MS. In the matter of experts and professionals, or how 
impossible it is to leave nothing unsaid. In Torstendhal R, Burrage $\mathrm{M}$, eds. The formation of professions: Knowledge, state and strategy. London, UK: Sage; 1990. pp 24-50.

12. Malin N. Professionalism, boundaries, and the workplace. New York, NY: Routledge; 2000.

13. Freidson E. Professional powers: A study of the institutionalization of formal knowledge. Chicago, Illinois: University of Chicago Press; 1988.

14. Sela-Sheffy R, Shlesinger M. Identity and status in the translational professions. Amsterdam: John Benjamins Publishing; 2011.

15. Nanacarrow SA, Borthwick AM. Dynamic professional boundaries in the healthcare workforce. Soc Health Ill 2005;27:897-919.

16. Saks M. The wheel turns? Professionalisation and alternative medicine in Britain. J Interprof Care 1999;12:129-38.

17. Foley L, Faircloth CA. Medicine as discursive resource: Legitimation in the work narratives of midwives. Sociol Health Ill 2003;25:165-84.

18. Timmons S, Tanner J. A disputed occupational boundary: Operating theatre nurses and operating department practitioners. Sociol Health Ill 2004:26:645-66.

19. Khalili, H Hall J, DeLuca S. Historical analysis of professionalism in western societies: Implications for interprofessional education and collaborative practice. J Interprof Care 2014;28:92-7.

20. Barnhart PA. The guide to national professional certification programs. Amherst, MA: HRD Press; 1997.

21. National Center for Complementary and Integrative Health.
Credentialing, licensing, and education. 2016. Available from: https://nccih.nih.gov/health/decisions/credentialing.htm Accessed: 19 February 2018.

22. Lindlof TR, Taylor BC. Qualitative communication research methods. Thousand Oaks, CA: Sage; 2011.

23. Academy of Nutrition and Dietetics. Why the Academy changed its name. [n.d.] Available from https://www.eatrightpro.org/leadership/academy-policies/strategic-plan/why-theacademy-changed-its-name Accessed: 19 February 2018.

24. Commission on Dietetic Registration. RDN Credential: Frequently Asked Questions. [n.d.] Available from: https://www. cdrnet.org/news/rdncredentialfaq Accessed: 19 February 2018.

25. Boeije H. A purposeful approach to the constant comparative method in the analysis of qualitative interviews. Qual Quant 2002;36:391-409.

26. Weick KE, Sutcliffe KM, Obstfeld D. Organizing and the process of sensemaking. Organ Sci 2005;16:409-21.

27. Ashcraft KL, Muhr SL, Rennstam J, Sullivan K. Professionalization as a branding activity: Occupational identity and the dialectic of inclusivity-exclusivity. Gend Work Organ 2012;19:467-88.

28. Shapiro L. Perfection salad : women and cooking at the turn of the century. New York, NY: Farrar, Straus, and Giroux; 1986.

29. Norander S, Mazer JP, Bates BR. “"D.O. or Die”: Identity negotiation among osteopathic medical students', Health Commun 2011;26:59-70. 